\title{
Delimiting the cryptic diversity and host preferences of Sycophila parasitoid wasps associated with oak galls using phylogenomic data
}

\author{
Y. Miles Zhang ${ }^{1,2}$, Sofia I. Sheikh ${ }^{3}$, Anna K.G. Ward ${ }^{3}$, Andrew A. Forbes ${ }^{3}$, Kirsten M. Prior ${ }^{4}$, \\ Graham N. Stone ${ }^{5}$, Michael W. Gates ${ }^{1}$, Scott P. Egan ${ }^{6}$, Linyi Zhang ${ }^{6,7}$, Charles Davis ${ }^{6,8}$, Kelly L. \\ Weinersmith $^{6}$, George Melika ${ }^{9}$, Andrea Lucky ${ }^{2}$ \\ 1. Systematic Entomology Laboratory, USDA-ARS, c/o National Museum of Natural \\ History, Washington, DC, 20013, USA \\ 2. Entomology and Nematology Department, University of Florida, Gainesville, FL, 32611 \\ USA
}

3. Department of Biology, University of Iowa, Iowa City, IA, 52242, USA

4. Department of Biological Sciences, Binghamton University, Binghamton, NY, USA

5. Institute of Evolutionary Biology, University of Edinburgh, Edinburgh, UK

6. Department of BioSciences, Rice University, Houston, TX, USA

7. Department of Ecology \& Evolutionary Biology, University of Toronto, Toronto, ON, Canada

8. Department of Entomology, Pennsylvania State University, University Park, PA, USA

9. Plant Health and Molecular Biology Laboratory, Directorate of Plant Protection, Budapest, Hungary

Corresponding author: Y. Miles Zhang, Yuanmeng.zhang@gmail.com

Keywords: Eurytomidae, Ultraconserved Elements, UCEs, DNA barcoding, Chalcidoidea, Cynipidae, Cynipini, Tritrophic interaction

\begin{abstract}
Cryptic species diversity is a major challenge for the species-rich community of parasitoids attacking oak gall wasps due to a high degree of sexual dimorphism, morphological plasticity, small size, and poorly known biology. As such, we know very little about the number of species present, nor the evolutionary forces responsible for generating this diversity. One hypothesis is that trait diversity in the gall wasps, including the morphology of the galls they induce, have evolved in response to selection imposed by the parasitoid community, with reciprocal selection driving diversification of the parasitoids. Using a rare continental scale data set of Sycophila parasitoid wasps reared from 44 species of cynipid galls from 18 species of oak across the US, we combined mitochondrial DNA barcodes, Ultraconserved Elements (UCEs), morphological, and natural history data to delimit putative species. We also generate the first large-scale assessment of ecological specialization and host association in this species-rich group with implications for evolutionary ecology and biocontrol. We find most Sycophila target multiple gall wasp species with similar gall morphologies and are generally associated with smaller galls. This result suggests that parasitoid wasps such as Sycophila have adaptations allowing them to exploit particular host trait combinations, while hosts with contrasting traits are resistant to attack. With our congruence-based method of species delimitation, our study has nearly doubled the number of Sycophila wasps among the lineages studied, which highlights the
\end{abstract}


need for taxonomic revision of Sycophila, as many species cannot be identified morphologically or by using molecular delimitation methods.

\section{Introduction}

Insect-induced galls on plants are veritable cradles of animal diversity, in part due to the many species that induce galls, but primarily because of the huge number of natural enemies that use the gall or the gall-former for shelter and sustenance (Price et al., 1987; Rohfritsch \& Shorthouse, 1982). An estimated 211,000 species across six insect orders, or $\sim 4 \%$ of the total estimated insect species induce galls (Espírito-Santo \& Fernandes, 2007). Galls are anomalous but highly-structured growths of plant material inside which the insect or its progeny can feed and any particular gall type may host up to $>20$ species of natural enemies (Askew et al., 2013; Forbes et al., 2016; Weinersmith et al., 2020). Though scientific study of tritrophic communities of host plant, gall wasp, and their natural enemies has been an area of active research for well over a century in the Western Palearctic region (Askew 1961; Bailey et al. 2009; Hayward \& Stone, 2005; Nicholls et al. 2017), Nearctic gall communities remain relatively poorly known.

One species rich arthropod community associated with galls that is well-suited for analysis of tritrophic relationships comprises the North American oak gall wasps (Cynipidae: Cynipini) and their associated hymenopteran natural enemies. The Cynipini gall oaks (Quercus spp.) and related Fagaceae, and have a global richness of $\sim 1000$ species in $\sim 50$ genera (Buffington et al., 2020). North America has a relatively high oak species richness (62 species; Cavender-Bares, 2019; Hipp et al., 2018; Manos \& Hipp 2021), and an associated high speciesrichness of oak galling cynipids ( 700 species North of Mexico, Burks 1979). Though the natural enemies of most North American oak gall wasps remain unknown, those studied in detail harbor high richness of 1-25 species of parasites, hyperparasites, and inquiline cynipids (herbivorous wasps that are obligate inhabitants of galls induced primarily by other cynipids) (Abe et al., 2007; Forbes et al., 2016; Hayward \& Stone, 2005; Schönrogge et al., 1996; Stone et al., 2012; Weinersmith et al., 2020). The parasitoid assemblages attacking regional sets of oak cynipid galls in the Western Palearctic typically overlap, and most of the parasitoids attack multiple host gall types, stimulating ongoing research in the processes that structure cynipidassociated parasitoid communities (Askew et al. 2013; Bailey et al. 2009).

Oak galls are frequently structurally complex, including characteristic sets of external traits (e.g. spines, hairs, nectar-secreting glands) and internal traits (e.g. internal airspaces, larval chambers that are suspended by radiating fibers or are free-rolling within the gall) (Figure 1), which represent the extended phenotypes of gall wasp genes (Abrahamson \& Weis, 1997; Bailey et al., 2009; Martinson et al., 2021; Nicholls et al., 2018; Stone \& Cook, 1998; Stone \& Schönrogge, 2003; Stone et al., 2002). Parasitoid enemies inflict high mortality on cynipid gall inducers, and the Enemy Hypothesis posits that these gall structural traits have likely evolved as defenses against natural enemies, which then drives reciprocal phenotypic evolution in relevant traits of parasitoid wasps, such as ovipositor lengths (Bailey et al., 2009; Price et al., 1987; Stone \& Schönrogge, 2003). The complexity of this system is further enriched by the cyclic parthenogenetic life cycles of most Cynipini, with obligate alternation between spring sexual and autumn asexual generations that induce morphologically distinct galls (often on different parts of the tree), which host different sets of natural enemies (Bailey et al., 2009; Stone \& Schönrogge, 2003). Most is known about the community structure and evolution of Western Palearctic oak gall wasp communities, which are relatively less diverse (around 149 oak gall wasp species, and around 110 parasitoid species), are widely distributed geographically, and have a long history of 
detailed taxonomic and ecological study (Ács et al., 2010, Askew et al. 2013, Hayward \& Stone 2005). In contrast, very little is known about North American oak cynipid communities, beyond the fact that they are clearly very species-rich, and are divided into distinct regional faunas (Weld $1957 ; 1959 ; 1960)$. In particular, and with some specific exceptions, we know very little about the taxonomy and biology of the parasitoid assemblages attacking North American oak cynipid galls. A general property of Western Palearctic cynipid communities is that most of the parasitoids involved attack multiple hosts, with some attacking over 100 gall types (Askew et al. 2013). The extent to which this is true of parasitoids in other global oak cynipid communities is unknown, but it is central to understanding the relationship between gall traits and parasitoid phenotypic evolution (Hayward \& Stone 2005, Bailey et al. 2009). The general hypothesis is that where gall wasps show high diversity in relevant gall traits, these will structure associated parasitoid assemblages.

One such associated group of parasitoids is the genus Sycophila (Hymenoptera: Eurytomidae, Figure 1A). Sycophila are cosmopolitan in their distribution, and known as parasitoids of endophytic insects such as gall inducers (Askew et al. 2006; 2013; Balduf 1932; Gómez et al., 2013), although a recently described parasitoid species is thought to be an ectoparasitoid of an eulophid gall on Smilax (Gates et al. 2020). Sycophila are often identified based on subtle coloration differences or based on host species and/or geographic differences (Balduf, 1932; Claridge, 1959). In addition, based on the literature, several described species have a wide host repertoire (e.g. Sycophila quercilanae $=19$ gall types, Sycophila occidentalis $=$ 12, Sycophila varians $=11$, Sycophila dorsalis $=9$ ), though lack of detailed study suggests that these host repertoire are likely underestimates and they are low compared to some western Palearctic species in oak galls (e.g. Sycophila biguttata $=80$, S variegata $=41$ ) (Askew et al. 2013; Balduf, 1932; Noyes, 2020). The high level of sexual dimorphism, morphological plasticity, and poorly known biology have further confounded species delimitation within this group (Davis et al., 2018; Gómez et al., 2013; Li et al., 2010; Lotfalizadeh et al., 2008; SmithFreedman et al., 2019). Inability to reliably identify Sycophila greatly hampers our understanding of the ecology and evolutionary history of their interactions with host galls, and also limits our understanding of Sycophila serving as potential biocontrol agents of pestiferous gall wasps such as the invasive Asian chestnut gall wasp, Dryocosmus kuriphilus (Dorado et al. 2020), or the native Zapatella davisae causing damage to black oaks in the New England area (Davis et al., 2018, Smith-Freedman et al., 2019).

Assessing species richness and revealing axes of host specialization for gall parasitoids requires a well-resolved and stable parasitoid taxonomy, which in turn requires an integrative approach. Single or multi locus approaches for taxon delimitation that use one or more genes such as the mitochondrial loci COI and Cytb have been used extensively to understand gall community diversity (Ács et al., 2010; Davis et al., 2018; Forbes et al., 2016; Gil-Tapetado et al., 2021; Kaartinen et al., 2010; MacEwen et al., 2020; Nicholls et al., 2018; Nicholls et al., 2010; 2018; Sheikh et al., 2021; Smith-Freedman et al., 2019; Ward et al., 2020; Weinersmith et al., 2020; Zhang Y.M. et al., 2014; 2019a), often in combination with morphological and/or ecological data. However, results from one or a few genes can be limited in resolution, and are known to be misleading due to confounding factors such as incomplete lineage sorting and introgression within both gall wasps and their associated parasitoids (Nicholls et al., 2012; Rokas et al., 2003; Zhang Y.M. et al., 2021). Nevertheless, molecular approaches remain attractive due to the demonstration of morphologically cryptic species in many parasitoid taxa with wide host repertoire, including members of oak gall wasp communities (Kaartinen et al. 2010; Nicholls et 
al. 2010, 2018). Rapid development and increased availability of tools designed to capture genomic DNA has led to increased use of genome-wide approaches to analysis of phylogenomics, biogeography, demography, host shifts, and tritrophic interactions of gall communities (Blaimer et al., 2020; Brandão-Dias et al., 2022, Bunnefeld et al., 2018; Driscoe et al., 2019; Samacá-Sáenz et al., 2020; Walton et al., 2021; Zhang Y.M. et al., 2020). Additionally, targeted capture methods such as Ultraconserved Elements (UCEs, Faircloth et al., 2012, reviewed in Zhang Y.M. et al., 2019b) have been shown to be complementary or superior to DNA barcodes for resolution of deep phylogenetic relationships and species delimitation in Hymenoptera, and can be amplified even from older museum samples (Branstetter \& Longino, 2019; Gueuning et al., 2020; Longino \& Branstetter, 2021; Prebus, 2021; Samacá-Sáenz et al., 2020). Thus UCEs are an appealing approach with which to validate species status in morphologically challenging taxa such as Sycophila.

The goals of this study are two-fold: 1) To delimit - using molecular, ecological, and morphological data - putative species among a representative collection of Sycophila collected from galls of 44 species of oak gall wasps from 18 oak tree species across the USA. Our sampling targeted two axes known to structure gall wasp-parasitoid associations: different gall wasp faunistic zones sensu Weld (Hayward \& Stone 2006), and hosts on different oak sections (Bailey et al. 2009). 2) To further delimit axes of adaptation ( host repertoire) and evolutionary histories of host use of North American Sycophila. We hypothesize that if parasitoids have cospeciated with their gall wasp hosts then galls with similar traits should host closely related Sycophila taxa. Alternatively, if parasitoid diversity is driven by host gall traits, we expect distantly related parasitoids to attack host galls with a set of similar traits. Whether phenotypically similar host galls are closely related or not depends on the phylogenetic pattern of host gall trait evolution: if host gall traits have evolved convergently in North America (as they are known to in the Western Palearctic; Stone and Cook 1998; Cook et al. 2002), we expect a single parasitoid to attack a set of unrelated but phenotypically similar host galls.

\section{Materials \& Methods}

\subsection{Taxon Sampling}

The Sycophila specimens used in this study were collected through long term collaborative efforts of the North American oak gall fauna by the authors and their respective collaborators, including many students. In brief, mature galls were collected and the inhabitants were reared from individual galls or from mass rearings of a single gall type. For each gall we recorded the host plant and we scored gall external and internal morphological traits (Table S2) using mature galls from collections at the Smithsonian National Museum of Natural History, using published terminologies from www.gallformers.org and existing literature (Deans et al., 2021; Weld, 1959). The trait set includes discrete binary or categorical characters describing gall position on plant (acorn, catkin, leaf, petiole, stem), attachment type (integral, detachable), external morphology (smooth, textured, leaf bract, sticky, spiny, wooly), and internal morphology (woody, hollow, fleshy, free-rolling, or radiating fiber). For these traits, integral attachment refers to galls whose tissues are broadly continuous with plant organs, such that the gall does not typically detach or dehisce from the plant when mature. External morphological traits include surface texture (for which the textured state indicates uneven surfaces that can be 
knobbled or rugose, Fig. 1A), and presence/absence of other traits (ant-recruiting nectaries, coatings of spines or wool, Fig. 1B, 1F) implicated in defense against parasitoids in other studies (Bailey et al. 2009; Nicholls et al. 2018). Internal morphological traits include the texture of gall tissues and two internal traits (free rolling larval chamber and a larval chamber suspended in the center of the gall by fine radiating strands, Fig. 1E) also associated with reduction in parasitoid oviposition accuracy (Bailey et al. 2009; Martinson et al. 2021). We scored mature gall size as a categorical variable, with 1 representing large $(>2 \mathrm{~cm})$ galls, 2 as medium $(0.5-2 \mathrm{~cm})$ galls, and 3 as small $(<0.5 \mathrm{~cm}$ ) galls (Table S2). We did not include the gall toughness as it can vary depending on when the gall was collected, we chose not to include them in the current study in order to standardize traits across different collectors/events. The biogeographic region is divided into Pacific Slopes, Southwest, and Eastern United States sensu Weld (1957, 1959, 1960).

Host trees were scored based on sections in Quercus sensu Manos \& Hipp (2021): Lobatae (red oaks), Protobalanus (intermediate or golden cup oaks), Quercus s.s. (white oaks), and Virentes (live oaks). Sycophila specimens were identified to species morphologically whenever possible using Balduf (1932) and double-checked with the type specimens at the US National Museum of Natural History (NMNH), Washington D.C. Where morphology-based identities could not be confidently assigned, we identified Sycophila specimens based on a combination of wing band, body coloration, and host information in cases where no matches were found. Detailed information on the associated characters and procedures are provided in Supplementary information. Representatives from each of the morphospecies were selected for downstream molecular analyses. One to several representatives of each Sycophila morphospecies from each different host gall type and/or widely separated locations were sequenced to sample the greatest possible degree of genetic variation based on host, geographic distance, and morphological variation. Voucher specimens are deposited at the NMNH and University of Iowa when possible, but some singletons were destructively sampled for DNA extraction. Habitus images were obtained using a Macropod imaging system consisting of a Canon EOS 5D Mark II digital SLR camera with a $65 \mathrm{~mm}$ macro lens, illuminated with a Dynalite MP8 power pack and lights. Images were captured using Visionary Digital proprietary software as TIF with the RAW conversion occurring in Canon Digital Photo Professional software. Image stacks were mounted with Helicon Focus 6.2.2. Images were edited in Adobe Photoshop.

\subsection{DNA Extractions, COI sequencing}

Representative specimens of Sycophila $(\mathrm{n}=89)$ were destructively sampled at either the University of Iowa or Rice University TX, USA. One third of specimens were extracted using the DNeasy Blood and Tissue Kit (Qiagen, Valencia, CA, USA), while later extractions used a CTAB/PCI extraction approach (Chen et al., 2010) as it yielded higher quality and concentration of DNA. Approximately 650bp of COI was amplified using either COI_pF2: 5' ACC WGT AAT RAT AGG DGG DTT TGG DAA 3' and COI_2437d: 5' GCT ART CAT CTA AAW AYT TTA ATW CCW G $3^{\prime}$ primers (Kaartinen et al., 2010), or, for most of the specimens, with an in-house forward primer Syco_2: 5' - TTC CWG ATA TRG CTT TYC C -3' and COI_2437d. The Syco_2 primer was designed to reduce degeneracy while still overlapping with the COI region amplified using the Kaartinen et al. (2010) primers. Forward and reverse Sanger sequencing was done on an ABM 3720 DNA Analyzer (Applied Biosystems, Foster City, CA) in the University of Iowa's Roy J. Carver Center for Genomics, and reads were processed in Geneious v8 (Biomatters Inc., San Diego, CA) for final consensus sequences. Additional COI sequences of Sycophila reared 
from asexual generation of Zapatella davisae (Smith-Freedman et al., 2019) and Belonocnema kinseyi (Forbes et al. 2016) were downloaded from GenBank for a total of 165 sequences, along with the sequence of Eurytoma longavena which was used as an outgroup (Zhang Y.M. et al., 2014).

\subsection{UCE Data Collection}

The UCE pipeline was conducted in the Laboratories of Analytical Biology (LAB) at the Smithsonian Institution's National Museum of Natural History (NMNH, Washington, DC, USA). The protocol largely follows the standard pipeline for capturing and enriching UCE loci from Hymenoptera (Branstetter et al., 2017; Zhang Y.M. et al., 2019b). Briefly, the DNA extracts from 30 samples were chosen based on high DNA quality, and the Kapa Hyper Prep library preparation kit (Kapa Biosystems Inc., Wilmington, MA, USA) was used along with TruSeq universal adapter stubs and 8-bp dual indexes (Glenn et al., 2019), combined with sheared genomic DNA and amplified using PCR. We followed the myBaits probes protocol (ArborBiosciences, Ann Arbor, MI, USA) for target enrichment of the pooled DNA libraries but instead used a 1:4 (baits:water) dilution of the custom Hymenoptera 2.5Kv2P developed by Branstetter et al. (2017) at $65^{\circ} \mathrm{C}$ for 24 hours. The combined library was sequenced on Illumina NovaSeq 6000 (150-bp paired-end, Illumina Inc., San Diego, CA, USA) at Novogene Corporation Inc. (Sacramento, CA, USA).

\subsection{UCE Data Processing and Alignment}

We used the PHYLUCE v1.6.8 pipeline (Faircloth, 2015) to process UCE data. Adapters were trimmed using Illumiprocessor and Trimmomatic (Bolger et al., 2014; Faircloth, 2013), and assembled using SPAdes v3.14.0 (Bankevich et al., 2012). The assemblies were aligned using MAFFT v7.490 (Katoh \& Toh, 2008), and trimmed using Gblocks (Castresana, 2000) using the following settings: $\mathrm{b} 1=0.5, \mathrm{~b} 2=0.5, \mathrm{~b} 3=12, \mathrm{~b} 4=7$. Additionally we used Spruceup v2020.2.19 $95 \%$ lognormal distribution or manual cutoff of select samples to remove any potentially misaligned regions as they can produce exaggerated branch lengths (Borowiec, 2019). We selected the $50 \%$ complete matrix with 1456 loci that are present in $\geq 50 \%$ of the taxa (15/30) as the final dataset. A $75 \%$ matrix (627 loci) was also tested to ensure topological consistency with a small set of more data-complete specimens. The topology of this tree was entirely concordant (data not shown). Phylogenetic summary statistics were calculated using AMAS v0.98 (Borowiec, 2016). Additionally, fragments of mitochondrial DNA COI were extracted from the UCE contigs using PHYLUCE to be used in conjunction with full COI barcodes whenever possible.

\subsection{Phylogenetic Analyses}

We conducted phylogenetic analyses under the maximum likelihood (ML) criterion with IQ-TREE v2.03 (Minh et al., 2020) for the COI data, using the best model (GTR+F+I+G4) chosen by ModelFinder (Kalyaanamoorthy et al., 2017), and 1000 ultrafast bootstrap replicates for nodal support (UFB, Hoang et al., 2017).

The UCE data were also analyzed using ML criterion with IQ-TREE, using partitions based on Sliding-Window Site Characteristics of Site Entropy (SWSC-EN) in PartitionFinder2 
(Lanfear et al., 2016; Tagliacollo \& Lanfear, 2018), and partitioned by using the rcluster algorithm in PartitionFinder2 via RAxML (Lanfear et al., 2014; Stamatakis, 2006). To assess nodal support, we performed 1000 UFB, along with "-bnni" to reduce risk of overestimating branch supports; and a Shimodaira-Hasegawa approximate likelihood-rate test (SH-aLRT, Guindon et al., 2010) with 1000 replicates. Only nodes with support values of UFB $\geq 95$ and SHaLRT $\geq 80$ were considered robust.

\subsection{Delimitation of Putative Species}

We used multiple molecular species delimitation methods in combination with geographical, ecological, and morphological data to delimit putative Sycophila species. Because many collections were made from different galls and host trees in the same geographic locations, correspondence between genetic differences, wing pattern differences, and different host associations provides strong indirect support for limited gene flow between sympatric individuals. A complete discussion of each putative Sycophila species, including representative body and wing images for most species, is provided in the supplemental materials.

For the COI data, we explored three popular molecular species delimitation methods: 1) Assemble Species by Automatic Partitioning (ASAP, https://bioinfo.mnhn.fr/abi/public/asap/, Puillandre et al., 2021), an extension of the Automatic Barcode Gap Discovery method (ABGD, Puillandre et al., 2012) was performed using the default setting using Kimura 2 parameter for distance. 2) The Bayesian Poisson Tree Processes (bPTP, https://species.h-its.org/, Zhang J.et al., 2013) was performed on the same dataset using the default settings of 200,000 MCMC generations, thinning of 100, and 0.1 burn-in. 3) The Generalized Mixed Yule Coalescent (GMYC, https://species.h-its.org/gmyc/, Pons et al., 2006) was performed on an ultrametric input tree generated in BEAST2 v. 2.2.7 (Bouckaert et al., 2014). The JC69 substitution model and a strict molecular clock with a fixed rate of 1.0, following a Yule model with a uniform distribution for "birthRate". The analysis ran for 10 million generations, with sampling every 1,000 generations. Convergence was confirmed with ESS above 200 in all categories using Tracer v1.7 (Rambaut et al., 2018). The resulting tree was analyzed using the single-threshold version of Splits R package (Ezard et al., 2009). Intra- and interspecific divergence among the species were calculated using MEGA11 (Tamura et al. 2021) under the Kimura-2-parameter (Kimura 1980).

For the UCE data, we also performed three species delimitation methods under the multispecies coalescent model (MSC). 1) We tested the full UCE dataset using SODA v1.0 (Rabiee \& Mirarab, 2020), which delimits species boundaries using quartet frequencies. 2) We performed allelic phasing on the UCE loci following Tutorial II of the PHYLUCE pipeline, which has been shown to improve species delimitation (Andermann et al., 2019). Single nucleotide polymorphisms (SNPs) were extracted from the phased UCE loci using SNP-sites V2.5.1 (Page et al., 2016), and analyzed using STACEY (Jones, 2017) as implemented in BEAST2 with model selection performed for each locus using the bModeltest option (Bouckaert \& Drummond, 2017). Species trees were estimated using a strict clock at 1.0 under the Fossilized Birth Death model (Heath et al., 2014), using a value of $1 \times 10^{-4}$ for the collapseHeight parameter, bdcGrowthRate $=\log$-normal $(\mathrm{M}=4.6, \mathrm{~S}=2)$; collapseWeight $=$ beta $($ alpha $=2$, beta $=2)$; popPriorScale $=\log$ normal $(\mathrm{M}=-7, \mathrm{~S}=2)$; relativeDeathRate = uniform (upper =1.0). The analysis ran for 10 million generations, sampling trees every 100,000 generations. Convergence was confirmed with 
ESS above 200 in all categories using Tracer v1.7 (Rambaut et al., 2018), and the sampled species trees were visualized with DensiTree 2.2.7 (Bouckaert, 2010). 3) We used BPP v4.3.8 (Yang, 2015) using a subset of 50 phased UCE loci with the greatest number of parsimonyinformative sites in order to reduce computational time using the Phyloch R package (Heibl, 2008). First, tau and theta parameters were estimated using the A00 analysis on the fixed SWSC tree, without delimitation. Using the resulting parameters, we performed the rjMCMC species delimitation algorithm 1 (species delimitation = 11221 ), with the number of MCMC generations to $300 \mathrm{~K}$, sampling every five generations, with a $25 \%$ burn in.

\subsection{Principal Coordinates Analysis of Gall Traits}

To uncover if groups of Sycophila species attack gall wasp species with particular gall morphology, we selected only the defensive traits (scored as 1 if present), and gall size (large gall size scored as 1 as putative defense). We calculated Gower's dissimilarity, which is appropriate for a mix of binary and categorical variables, on a gall wasp species $\times$ trait matrix (Laliberte \& Legendre 2010). We then performed a principal coordinates analysis (PCoA) and projected gall wasp species in trait space by creating a biplot with PCoA1 and PCoA2 (Dehling et al. 2015). Next, to project Sycophila species in interacting gall wasp species trait space (i.e., "interaction" trait space), for each Sycophila species (Table S5), we calculated the interaction centroid as the center of gall wasp species that Sycophila species interact with. Finally, we plotted the centroids for each Sycophila species in a biplot, along with loadings representing gall wasp traits that we extracted from a gall wasp biplot. We used R v4.1.1 (R Core Team 2021) and the following R packages, 'labdsv', 'vegan', and 'ape', to perform analyses and make biplots (Roberts 2019, Oksanen et al. 2020, Paradis et al. 2021).

Next, to test if distances in interaction trait space between paired Sycophila species are correlated with evolutionary distances, we created a matrix of Euclidean distances between each pair of Sycophila species in interaction trait space (smaller values meaning Sycophila species are attacking galls with similar defensive traits). We also created a matrix of pairwise interspecific genetic distances (a proxy for relatedness among Sycophila species) using the Kimura 2parameter model (Kimura 1980) using default settings in MEGA 11(Tamura et al. 2021). We then performed a Mantel test between the evolutionary distance matrix and the interaction trait distance matrix in R using in the package 'vegan' (Oksanen et al. 2020). If closely related species of Sycophila cluster together on gall trait space, it would suggest they likely have cospeciated with their host. Conversely, if distantly related species of Sycophila are attacking galls with similar traits, this would suggest they are convergently targeting specific gall traits to overcome. Mantel tests are used to study relationships among dissimilarities in dissimilarity matrices (Legendre et al. 2015). Recent papers have raised concerns about the power of the Mantel test in specific contexts (Harmon \& Glor 2010, Legendre \& Fortin 2010, Guillot \& Rousset 2013). One concern is the inflation of Type I error, including for dissimilarity matrices of hierarchical phylogenetic distances (Harmon \& Glor 2010). Since we find no relationship between genetic distance and interaction trait distances this issue is not a concern in the interpretation of our results. Despite the controversy of Mantel tests in certain contexts, they are still used to compare genetic and trait distances among populations and species (e.g. Borcard \& Legendre 2011, Schwallier et al. 2015). 


\section{Results}

\subsection{COI Data}

The final COI dataset consisted of 165 Sycophila specimens, reared from 44 different oak gall wasp species (27 asexual generation, 17 sexual generation) collected on 18 different oak species. Most sequence lengths were 655bp, except for the Z. davisae parasitoids from GenBank, which were $414 \mathrm{bp}$ due to primer differences, and barcode slices from the UCE contigs which ranged from 193-655bp.

The three species delimitation programs, ASAP, bPTP, and GMYC, delimited 35 (7 sequences removed due to not overlapping), 42, and 40 putative species (Figure 2), respectively. In instances where sequence-based delimitation methods disagreed (S. nr. foliatae2, S. nr. flava, S. $n r$. globuli, S. globuli), we used the most conservative estimate, reducing the final number of putative species down to 35 (Figure 2, S1). It is worth noting that some putative species have low bootstrap support (e.g. S. nr. foliatae-1 and S. globuli, Fig. S3), or could represent population level genetic differences without clear host or geographical differences (e.g. S. sp1, S. sp2, Fig. 2 ). The intraspecific divergence ranged from $0.0-4.3 \%$ (Table S3), while the interspecific divergence ranged from $4.0-19.3 \%$ (Table S4).

Host richness of the putative 35 Sycophila species ranged from 1-12 gall wasp species, we categorized them as 24 extreme specialists ( 1 host), 10 specialists (2-11 hosts), and one generalist (11+ hosts) following Bailey et al. (2009) (Table 1). Sycophila quercilanae had the broadest host repertoire, being reared from 12 gall species from eight different tree species. Two species of Sycophila (S. dubia, S. globuli) with more than one wasp host species were restricted to hosts from the same genus, while others such as $S$. quercilanae are recorded from hosts in eight different wasp host genera. In terms of the traits of gall wasps attacked by individual putative Sycophila species, 2-5 external and 1-3 internal gall morphological traits are observed, found on 1-2 different plant tissues. Most putative Sycophila species were reared exclusively from asexual generation galls (20/32), while the remaining species were either reared exclusively from sexual generation galls (6 species), or were reared from both sexual and asexual generations (6 species; Fig. 2). Tree association for Sycophila species ranged from 1-7 oak tree species, reflecting either one or two Quercus Sections. Most putative species (28/35) were reared from galls on only one Quercus Section, while two species (Fig. 2, S1, S. foliatae, $S$. flava/texana) were associated with Sections Quercus s.s. and Virentes, which together form a monophyletic group within the subgenus Quercus s.l. (Hipp et al., 2018), and six species were associated with both Sections Quercus and Lobatae.

\subsection{UCE Data}

The concatenated UCE 50\% matrix was 588,371 bp long, after removing the 0.95 lognormal cutoffs using AMAS, the final matrix is 113,221 variable sites (19.2\%) and 34,782 parsimony informative sites $(5.9 \%)$, with $41.2 \%$ missing data.

Species delimitations using UCE data are largely congruent with COI-based results for 19 of the 35 morphospecies, where both data types are available. UCE data supported 22 putative species using the unphased data in SODA and with phased SNPs of the top 50 most parsimoniously informative loci in BPP, while STACEY identified 17 species using the full set of phased SNPs (Fig. 3). The differences between the UCE and COI datasets arise due to UCE- 
based lumping of the following COI-supported morphospecies (Table 1): S. pezomachiodes (YMZ056) \& S.lobatae (YMZ052), and S. nr. nigriceps-2 (YMZ041) \& S. nr. occidentalis (YMZ021). Sycophila foliatae also differs in the UCE data as it was recovered from two separate clades, once grouped with $S$. $n r$. foliatae-1 as mentioned above (YMZ025), and again as sister to S. $n r$. lanae (YMZ031/32). Nearly all nodes within the UCE dataset are strongly supported by ultrafast bootstraps and SH-aLRT (Fig. S4). Putative species were grouped together regardless of sampling location (e.g. S. nr. dubia/globuli from CA and IA, S. texana from FL and TX), thus ruling out potential phylogeographic substructures at the population level biasing accurate species delimitation.

\subsection{PCoA}

We found that pairwise distances in interaction trait space between Sycophila pairs was not correlated with evolutionary distances (Mantel $r=-0.010, p=0.577$, Fig. S5), i.e. distantly related Sycophila species are found to be attacking galls with similar defensive traits. Additionally, sets of Sycophila species interact with galls with different internal tissues and structures as they associate with loadings representing galls with fleshy tissue, woody tissue, or that are hollow (Fig. 4), and more Sycophila species attacked small galls (positive coordinates on PCoA1). External defenses are plotted in the middle of the biplot, where few Sycophila species 428 are projected.

\section{Discussion}

431

432

433

434

435

436

437

438

439

440

441

442

443

444

445

446

447

448

449

450

451

\subsection{Sycophila host specificity}

We used a combination of molecular data (COI, UCEs) and extensive ecological data to determine the species richness and host repertoire of Sycophila parasitoids associated with oak cynipid galls in North America. Based on our conservative delimitations of potential species, most Sycophila are oligophagous species that have limited host repertoire across host tree relationships and gall morphology (Table 1, Figures 2, 3). For example, 11/17 species represented in the UCE phylogeny were only found on one oak Section (Figure 3), while certain species (S. nr. nigriceps/nr. occidentalis/sp4/globuli) were reared from galls from multiple oak Sections but with similar morphology (e.g., all woody stem galls). The true host breadths of some or all of these Sycophila species are likely higher given that we did not sample from all of the 700+ described North American oak gall wasp species, nor did we sample across the entire range of the included species, and we still don't know the full cynipid diversity in North America. Unlike the host gall wasps, which are largely restricted to inducing galls on related oak trees and often in the same oak Section (Cook et al., 2002; Stone et al. 2009; Melika et al. 2010; Tang et al., 2011), at least some Sycophila species specialize on aspects of the gall itself. This result is consistent with previous works examining host traits of another koinobiont endoparasitoid Euderus set, which is reared from galls in a variety of genera and from different oak tree Sections, but apparently only successfully attacks integral leaf and stem galls lacking external defenses (Ward et al., 2019). 
In terms of what these data reveal about Sycophila overcoming host gall defenses, most Sycophila species (20/35) were reared from galls with minimal external defenses and a variety of different internal gall textures (Figure 2). By comparison, galls with external spiny, wooly, or nectar-secretions were attacked only by a smaller subset (13/35) of Sycophila species. Similarly, galls with internal defenses such as radiating internal fibers or with free-rolling larval chambers, as seen in galls of some Amphibolips and Dryocosmus spp. in our study, were only attacked by a single species of Sycophila, whereas the woody or fleshy internal morphologies in typical galls were attacked by multiple species. Galls that possess external or internal defenses can be useful in reducing or even excluding parasitoids such as Sycophila. The biplot also showed that the Sycophila associated gall traits are convergent as distantly related species are found attacking galls with similar defenses. Future studies could be conducted focusing on intensive sampling at a smaller geographic scale, to help clarify whether the patterns we observed in our dataset are influenced by sampling bias. As the galls were often collected haphazardly based on availability, the rate of parasitism by Sycophila (and other parasitoids) cannot be accurately estimated for each of the gall types.

Another important aspect of a parasitoid's ability to attack hosts is phenology, including the developmental timing of the gall and(or) the seasonal timing of the host plant. The optimal temporal window for oviposition into a particular species of gall may often be limited to the time before the gall grows too large for ovipositors to reach the insect inside. Based on the PCoA analysis (Fig. 4) more Sycophila species attacked smaller galls, which are likely easier to reach given the relatively shorter ovipositor length when compared with other parasitoids such as Torymus. The majority of our Sycophila were collected from asexual generation galls found in autumn (27/44), which are often more conspicuous and have a longer growing period, compared to sexual generation galls (17/44) which often develop rapidly in spring on ephemeral resources such as catkins. Nevertheless, we did rear some Sycophila species only from the sexual generations (S. nr. lanae, S. nr. foliatae-1, S. wiltzae, S. sp5-1, S. sp5-2, S. flava, and S. texana) or from galls from both generations (S. foliatae, nr. lobatae-2, S. sp3, S. sp4, S. marylandica, and S. nr. dubia/globuli). Some of these parasitoids might therefore be bi- or multivoltine, having multiple generations a year attacking different galls at various stages of development (Askew 1965). Bivoltinism is known for several of the chalcids attacking European oak cynipid galls, including species in which the two generations have different ovipositor lengths, allowing them to attack different gall morphologies (Askew 1965). Studies have also shown that the emergence phenology of sympatric gall wasp populations can differ based on phenological differences between host plants, which can reduce gene flow between host-associated populations (Hood et al., 2019; Zhang L. et al., 2019). While some studies have shown that temporal isolation can cascade across multiple trophic levels and potentially drive the speciation of some parasitoid communities (Hood et al., 2015, Zhang L. et al. 2019), the study by Sinclair et al. (2015) showed that different oak galls respond differently by host phenology, and that being a generalist requires maintaining phenological flexibility.

Despite recent advances in understanding of basal relationships between tribes within the Cynipidae (Blaimer et al., 2020; Brandão-Dias et al., 2022; Zhang Y.M. et al., 2020) and work on relationships between gall wasp lineages in the Western Palearctic (Stone et al. 2009), the status of oak gall wasp taxonomy and phylogenetics in North America is incomplete and many genera are para- or even polyphyletic. Similarly, the general patterns of Sycophila host preference listed above do not account for interactions with other natural enemies within the gall system including hyperparasitoids, which can target and kill mature Sycophila larvae, and 
therefore affect the patterns we observe in terms of adult emergence. Unfortunately, much of these interactions among North American oak gall communities remains unknown aside from Ormyrus (Sheikh et al., 2021), but we hope these studies will lay the foundations for, and generate interest in, future investigations that can clarify these complex community structures.

\subsection{Species delimitation of Sycophila}

The resolution offered by UCE data is promising for generating robust phylogenies at the species/population level, especially with allelic phasing and the extraction of SNPs (Andermann et al., 2019; Gueuning et al 2020; Prebus 2021). Effects of potential gene flow, incomplete lineage sorting and/or introgression can be seen in the form of incongruencies within the UCE trees (Figure 2, S. globuli, S. nr. foliatae-1, S. nr. lanae, S. foliatae), as the two alleles of the same sample were not recovered as sisters to each other. These patterns of mitonuclear discordance have been observed in other studies of other oak gall wasp systems (Nicholls et al. 2012; Zhang Y.M. et al. 2021). We acknowledge the potential inflation of putative species richness based on the molecular species delimitation methods used (Chambers \& Hillis, 2020; Luo et al., 2018; Sukumaran \& Knowles, 2017), especially when there are no clear barcoding gaps in some species (eg. $4.3 \%$ intraspecific divergence within $S$. flava/texana, while $S$. nr. foliatae-2 and $S$. nr. lanae have only $3.9 \%$ interspecific divergence). UCE loci have been shown to be useful for species delimitation in some Hymenoptera (Branstetter \& Longino, 2019; Gueuning et al., 2020; Longino \& Branstetter, 2021), and in our study to be more conservative than the traditional DNA barcodes as multiple COI morphospecies were lumped together based on UCE results (Figures 2, 3). However, our exploration using phased SNPs and subset of UCE loci using various delimitation software corroborates findings from other phylogenomic species delimitation studies that some taxa can remain contentious (Prebus, 2021; Samacá-Sáenz et al., 2020). It is likely that the discordance within our UCE data such as the $S . n r$. foliatae-1/S. $n r$. lanae/S. foliatae clade is the result of over-splitting and might represent a single variable species, introgression, or a recent/ongoing divergence. Future studies should focus on wider geographic sampling for these challenging complexes using a population genomic approach to detect geographical substructures.

Nevertheless, it is clear that the North American Sycophila is in need of taxonomic revision, and while this is beyond the scope of the current study, the molecular evidence presented here and in previous studies (Davis et al., 2018; Smith-Freedman et al., 2019) has shown that body coloration or wing band shape that was used by Balduf (1932) can vary significantly among conspecifics, and are therefore not reliable diagnostic characters. This is especially evident in species with a small wing band (e.g. S. quercilanae, S. pezomachiodes, $S$. marylandica, $S$. wiltzae), where the females have seemingly diagnostic color patterns, but the males look nearly identical and cannot be identified. Thus, a thorough exploration of the morphological, ecological, and biogeographic data combined with phylogenomic data and more complex species delimitation methods are needed to be able to determine the species limits within the genus Sycophila. Additional studies on the biology of different North American Sycophila species could potentially explain the difference between host repertoires, as there are reports of both endoparasitism (Claridge 1959; Gómez et al., 2013), which are often specialists due to the need to overcome host immune defenses, and ectoparasitism (Gates et al. 2020), many of which have less specialization and are therefore generalists. 


\subsection{Conclusions}

Hymenopteran parasitoids are likely one of the most diverse groups of animals (Forbes et al., 2018), yet much of their biology and ecology remains unknown due to their small size and often problematic taxonomy. Using detailed ecological records combined with genomic data, we were able to better understand the species richness and host preferences of a small subset of Sycophila parasitoids associated with oak galls in the USA. Many Sycophila species are oligophagous, attacking galls that have less defensive traits and are smaller in size. The use of UCEs to delimit species is shown to be more conservative than traditional COI DNA barcoding, although careful interpretation of the data in combination with ecological evidence is still needed due to potential oversplitting, even though the more contentious complexes within the tree also offer some exciting areas to explore parasitoid evolution. The oak gall system offers an exciting insight into the evolution of tritrophic systems and shares many similarities with other concealed herbivore communities such as leaf miners and stem borers, many of which are of economic concern. With more long-term data collection the North American gall wasp system can develop into a fantastic model system that can be used to address broad biological questions such as speciation and multi-trophic interactions.

\section{Acknowledgements}

We would also like to thank Maureen Turcatel, Bernardo Santos, Karen Neves, and Matt Prebus for providing time and expertise for UCE library preparation and downstream analyses. We acknowledge University of Florida Research Computing and the Smithsonian Institution High Performance Cluster (SI/HPC) for providing computational resources and support that have contributed to the research results reported in this publication. YMZ was funded by the Theodore Roosevelt Memorial Grant provided by the American Museum of Natural History and Oak Ridge Institute for Science and Education (ORISE) fellowship. Funding to AKGW was awarded by the American Genetic Association. Mention of trade names or commercial products in this publication is solely for the purpose of providing specific information and does not imply recommendation or endorsement by the USDA. USDA is an equal opportunity provider and employer.

\section{Author Contributions}

Y.M.Z., S.I.S., A.K.G.W., and A.A.F. designed the study. All authors made collections and/or reared animals. Y.M.Z., S.I.S., A.K.G.W., and C.D. obtained the sequence data. Y.M.Z., S.I.S., A.K.G.W., A.A.F., and K.M.P. conducted the analyses, Y.M.Z., S.I.S., A.A.F., K.M.P., and G.N.S. wrote the manuscript. All authors contributed to specimens, revisions and approved the final manuscript.

\section{Data Availability Statement}


The COI data is available on GenBank (MZ905524-905639), raw UCE sequences available on SRA (SAMN20307313-20307342). UCE matrix for phylogenetic analyses, and input file for STACEY/BPP are available on the Dryad Digital Repository at: XXX.

\section{References}

592

593

594

595

596

597

598

599

600

601

602

603

604

605

606

607

608

609

610

611

612

613

614

615

616

617

618

619

620

621

622

623

624

625

626

627

628

629

630

631

632

633

634

635

636

637

638

639

640

Abe, Y., Melika, G., \& Stone, G. N. (2007). The diversity and phylogeography of cynipid gallwasps (Hymenoptera: Cynipidae) of the Oriental and Eastern Palearctic regions, and their associated communities. Oriental Insects, 41(1), 169-212. doi:10.1080/00305316.2007.10417504

Abrahamson, W. G., \& Weis, A. E. (1997). Evolutionary ecology across three trophic levels: Goldenrods, gallmakers, and natural enemies (Vol. 29): Princeton University Press.

Ács, Z., Challis, R. J., Bihari, P., Blaxter, M., Hayward, A., Melika, G., . . Stone, G. N. (2010). Phylogeny and DNA barcoding of inquiline oak gallwasps (Hymenoptera: Cynipidae) of the Western Palaearctic. Molecular Phylogenetics and Evolution, 55(1), 210-225. doi:10.1016/j.ympev.2009.12.004

Andermann, T., Fernandes, A. M., Olsson, U., Topel, M., Pfeil, B., Oxelman, B., . . . Antonelli, A. (2019). Allele phasing greatly improves the phylogenetic utility of ultraconserved elements. Systematic Biology, 68(1), 32-46. doi:10.1093/sysbio/syy039

Askew R. R. (1961). On the biology of the inhabitants of oak galls of Cynipidae (Hymenoptera) in Britain. Transactions of the Society for British Entomology, 14, 237-268.

Askew, R.R. (1965). The biology of the British species of the genus Torymus Dalman (Hymenoptera: Torymidae) associated with galls of Cynipidae (Hymenoptera) on oak, with special reference to alternation of forms. Transactions of the Royal Entomological Society of London, 9, 217-232.

Askew R.R., Melika G, Pujade-Villar, J., Schönrogge, K., Stone, G.N., \& Nieves-Aldrey, J.-L. (2013). Catalogue of parasitoids and inquilines in cynipid oak galls in the West Palaearctic. Zootaxa, 3643(1), 1-133. doi: 10.11646/zootaxa.3643.1.1

Bailey, R., Schonrogge, K., Cook, J. M., Melika, G., Csóka, G., Thuroczy, C., \& Stone, G. N. (2009). Host niches and defensive extended phenotypes structure parasitoid wasp communities. PLoS biology, 7(8), e1000179. doi:10.1371/journal.pbio.1000179

Balduf, W. V. (1932). Revision of the chalcid files of the tribe Decatomini (Eurytomidae) in America north of Mexico. Proceedings of the United States National Museum, 79, 1-95.

Bankevich, A., Nurk, S., Antipov, D., Gurevich, A. A., Dvorkin, M., Kulikov, A. S., . . Prjibelski, A. D. (2012). SPAdes: A new genome assembly algorithm and its applications to single-cell sequencing. Journal of Computational Biology, 19(5), 455-477. doi:10.1089/cmb.2012.0021

Blaimer, B. B., Gotzek, D., Brady, S. G., \& Buffington, M. L. (2020). Comprehensive phylogenomic analyses rewrite the evolution of parasitism within cynipoid wasps. BMC Evolutionary Biology, 20(1), 155. doi:10.1186/s12862-020-01716-2

Bolger, A. M., Lohse, M., \& Usadel, B. (2014). Trimmomatic: A flexible trimmer for Illumina sequence data. Bioinformatics, 30(15), 2114-2120. doi:10.1093/bioinformatics/btu170

Borcard, B., \& Legendre, P. (2012). Is the Mantel correlogram powerful enough to be useful in ecological analysis? A simulation study. Ecology 93,1473-1481. https://doi.org/10.1890/11-1737.1

Borowiec, M. L. (2016). AMAS: A fast tool for alignment manipulation and computing of summary statistics. PeerJ, 4, e1660. doi:10.7717/peerj.1660

Borowiec, M. L. (2019). Spruceup: Fast and flexible identification, visualization, and removal of outliers from large multiple sequence alignments. Journal of Open Source Software, 4(42). doi:10.21105/joss.01635

Bouckaert, R. R. (2010). DensiTree: Making sense of sets of phylogenetic trees. Bioinformatics, 26(10), 1372-1373. doi:10.1093/bioinformatics/btq110

Bouckaert, R. R., \& Drummond, A. J. (2017). bModelTest: Bayesian phylogenetic site model averaging and model comparison. BMC Evolutionary Biology, 17(1), 1-11. doi:10.1186/s12862-017-0890-6

Bouckaert, R. R., Heled, J., Kühnert, D., Vaughan, T., Wu, C.-H., Xie, D., . . Drummond, A. J. (2014). BEAST 2: a software platform for Bayesian evolutionary analysis. PLoS Computational Biology, 10(4), e1003537. doi:10.1371/journal.pcbi.1003537

Brandão-Dias, P.F.P., Zhang, Y.M., Pirro, S., Vinson, C.C., Weinersmith, K.L., Ward, A.K.G., Forbes, A.A. \& Egan, S.P. (2022). Describing biodiversity in the genomics era: A new species of Nearctic Cynipidae gall wasp and its genome. Systematic Entomology, 47: 94-112. https://doi.org/10.1111/syen.12521 
Branstetter, M. G., \& Longino, J. T. (2019). Ultra-conserved element phylogenomics of New World Ponera (Hymenoptera: Formicidae) illuminates the origin and phylogeographic history of the Endemic Exotic Ant Ponera exotica. Insect Systematics and Diversity, 3(2), 1. doi:10.1093/isd/ixz001

Branstetter, M. G., Longino, J. T., Ward, P. S., Faircloth, B. C., \& Price, S. (2017). Enriching the ant tree of life: enhanced UCE bait set for genome-scale phylogenetics of ants and other Hymenoptera. Methods in Ecology and Evolution, 8(6), 768-776. doi:10.1111/2041-210x.12742

Buffington, M. L., Forshage, M., Liljeblad, J., Tang, C.-T., \& van Noort, S. (2020). World Cynipoidea (Hymenoptera): A Key to Higher-Level Groups. Insect Systematics and Diversity, 4(4). doi:10.1093/isd/ixaa003

Bunnefeld, L., Hearn, J., Stone, G. N., \& Lohse, K. (2018). Whole-genome data reveal the complex history of a diverse ecological community. Proceedings of the National Academy of Sciences of the United States of America, 115(28), E6507-E6515. doi:10.1073/pnas.1800334115

Burks, B.D. (1979). Superfamily Cynipoidea. In K.V. Krombein, P.D. Hurd, Jr., D.R. Smith, \& B.D. Burks. (Eds.), Catalog of Hymenoptera in America North of Mexico. Vol. 1. Symphyta and Apocrita. (pp. 1045-1107). Smithsonian Institution Press, Washington, DC.

Castresana, J. (2000). Selection of conserved blocks from multiple alignments for their use in phylogenetic analysis. Molecular Biology and Evolution, 17(4), 540-552. doi:10.1093/oxfordjournals.molbev.a026334

Cavender-Bares, J. (2019). Diversification, adaptation, and community assembly of the American oaks (Quercus), a model clade for integrating ecology and evolution. New Phytologist, 221(2), 669-692. doi:10.1111/nph.15450

Chambers, E. A., \& Hillis, D. M. (2020). The multispecies coalescent over-splits species in the case of geographically widespread taxa. Systematic Biology, 69(1), 184-193. doi:10.1371/journal.pone.0011963

Chen, H., Rangasamy, M., Tan, S. Y., Wang, H., \& Siegfried, B. D. (2010). Evaluation of five methods for total DNA extraction from western corn rootworm beetles. PLoS One, 5(8), e11963.

Claridge, M. F. (1959). A contribution to the biology and taxonomy of the British species of the genus Eudecatoma Ashmead (= Decatoma Auctt. nec Spinola)(Hym., Eurytomidae). Transactions of the Society for British Entomology, 13(9), 149-168.

Cook, J. M., Rokas, A., Pagel, M., \& Stone, G. N. (2002). Evolutionary shifts between host oak sections and host $\square$ plant organs in Andricus gallwasps. Evolution, 56(9), 1821-1830.

Davis, M. J., Andersen, J. C., \& Elkinton, J. (2018). Identification of the parasitoid community associated with an outbreaking gall wasp, Zapatella davisae, and their relative abundances in New England and Long Island, New York. Ecology and Evolution, 9(1), 19-25. doi:10.1002/ece3.4543

Deans, A. R., Nastasi, L., \& Montelongo, D. C. (2021). Glossary of gall terms V5. doi:10.26207/22e9-ck06

Dehling, D.M., Jordano, P., Schaefer, H.M., Bohning-Gaese, K., \& Schleuning, M. (2015). Morphology predicts species' functional roles and their degree of specialization in plant-frugivore interactions. Proceedings of the Royal Society B, 283, 20152444. doi:10.1098/rspb.2015.2444

Dorado, F.J., Pujade-Villar, J., Muñoz-Adalia, E.J., Vinagrero, J.C., Diez-Casero, J.J., \& Fernández-Fernández, M.M. (2020). Characterization of native parasitoid community associated with the invasive pest Dryocosmus kuriphilus (Hymenoptera: Cynipidae) in Cantabria (northern Spain). Scandinavian Journal of Forest Research, 35(7), 334-340. doi:10.1080/02827581.2020.1808055

Driscoe, A. L., Nice, C. C., Busbee, R. W., Hood, G. R., Egan, S. P., \& Ott, J. R. (2019). Host plant associations and geography interact to shape diversification in a specialist insect herbivore. Molecular Ecology, 28(18), 4197-4211. doi:10.1111/mec.15220

Espírito-Santo, M. M., \& Fernandes, G. W. (2007). How many species of gall-inducing insects are there on earth, and where are they? Annals of the Entomological Society of America, 100(2), 95-99. doi:10.1603/00138746(2007)100[95:HMSOGI]2.0.CO;2

Ezard, T., Fujisawa, T., \& Barraclough, T. G. (2009). SPLITS: Species' limits by threshold statistics. Retrieved from https://rdrr.io/rforge/splits/

Faircloth, B. C. (2013). Illumiprocessor: A trimmomatic wrapper for parallel adapter and quality trimming. Retrieved from http://dx.doi.org/10.6079/J9ILL

Faircloth, B. C. (2015). PHYLUCE is a software package for the analysis of conserved genomic loci. Bioinformatics, 32(5), 786-788. doi:10.1093/bioinformatics/btv646

Faircloth, B. C., Branstetter, M. G., White, N. D., \& Brady, S. G. (2015). Target enrichment of ultraconserved elements from arthropods provides a genomic perspective on relationships among Hymenoptera. Molecular Ecology Resources, 15(3), 489-501. doi:/10.1111/1755-0998.12328 
Faircloth, B. C., McCormack, J. E., Crawford, N. G., Harvey, M. G., Brumfield, R. T., \& Glenn, T. C. (2012). Ultraconserved elements anchor thousands of genetic markers spanning multiple evolutionary timescales. Systematic Biology, 61(5), 717-726. doi:10.1093/sysbio/sys004

Forbes, A. A., Bagley, R. K., Beer, M. A., Hippee, A. C., \& Widmayer, H. A. (2018). Quantifying the unquantifiable: Why Hymenoptera, not Coleoptera, is the most speciose animal order. BMC Ecology, 18(1), 21. doi:10.1186/s12898-018-0176-x

Forbes, A. A., Hall, M. C., Lund, J., Hood, G. R., Izen, R., Egan, S. P., \& Ott, J. R. (2016). Parasitoids, hyperparasitoids, and inquilines associated with the sexual and asexual generations of the gall former, Belonocnema treatae (Hymenoptera: Cynipidae). Annals of the Entomological Society of America, 109(1), 49-63. doi:10.1093/aesa/sav112

Gates, M.W., Zhang, Y.M., \& Buffington, M.L., (2020). The great greenbriers gall mystery resolved? New species of Aprostocetus Westwood (Hymenoptera, Eulophidae) gall inducer and two new parasitoids (Hymenoptera, Eurytomidae) associated with Smilax L. in southern Florida, USA. Journal of Hymenoptera Research, 80, 71-98. doi: 10.3897/jhr.80.59466.

Gil $\square$ Tapetado, D., Durán $\square$ Montes, P., García $\square$ París, M., López $\square$ Estrada, E.K., Sánchez $\square$ Vialas, A., Jiménez $\square$ Ruiz, Y., Gómez, J.F., \& Nieves $\square$ Aldrey, J.L. (2021). Host specialization is ancestral in Torymus (Hymenoptera, Chalcidoidea) cynipid gall parasitoids. Zoologica Scripta, 51, 91-118. doi: $10.1111 /$ zsc. 12515

Glenn, T. C., Nilsen, R. A., Kieran, T. J., Sanders, J. G., Bayona-Vásquez, N. J., Finger, J. W., . . Faircloth, B. C. (2019). Adapterama I: Universal stubs and primers for 384 unique dual-indexed or 147,456 combinatorially-indexed Illumina libraries (iTru \& iNext). PeerJ, 7, e 7755. doi:10.7717/peerj.7755

Gómez, J. F., Nieves-Aldrey, J. L., \& Stone, G. N. (2013). On the morphology of the terminal-instar larvae of some European species of Sycophila (Hymenoptera: Eurytomidae) parasitoids of gall wasps (Hymenoptera: Cynipidae). Journal of Natural History, 47(47-48), 2937-2960. doi:10.1080/00222933.2013.791937

Gueuning, M., Frey, J. E., \& Praz, C. (2020). Ultraconserved yet informative for species delimitation: Ultraconserved elements resolve long-standing systematic enigma in Central European bees. Molecular Ecology, 29(21), 4203-4220. doi:10.1111/mec.15629

Guillot, G. \& Rousset, F. (2013). Dismantling the Mantel tests. Methods in Ecology and Evolution, 4, 336344. doi:10.1111/2041-210x.12018

Guindon, S., Dufayard, J.-F., Lefort, V., Anisimova, M., Hordijk, W., \& Gascuel, O. (2010). New algorithms and methods to estimate maximum-likelihood phylogenies: Assessing the performance of PhyML 3.0. Systematic Biology, 59(3), 307-321. doi:10.1093/sysbio/syq010

Harmon, L.J., Glor, R.E. (2010). Poor statistical performance of the mantel test in phylogenetic comparative analyses. Evolution, 64, 2173-2178. doi:10.1111/j.1558-5646.2010.00973.x

Hayward, A., \& Stone, G. N. (2005). Oak gall wasp communities: Evolution and ecology. Basic and Applied Ecology, 6(5), 435-443. doi:10.1016/j.baae.2005.07.003

Hayward, A. \& Stone, G.N. (2006). Comparative phylogeography across two trophic levels: The oak gall wasp Andricus kollari and its chalcid parasitoid Megastigmus stigmatizans. Molecular Ecology, 15, 479-489. doi: 10.1111/j.1365-294X.2005.02811.x

Heath, T. A., Huelsenbeck, J. P., \& Stadler, T. (2014). The fossilized birth-death process for coherent calibration of divergence-time estimates. Proceedings of the National Academy of Sciences of the United States of America, 111(29), E2957-2966. doi:10.1073/pnas.1319091111

Heibl, C. (2008). PHYLOCH: R language tree plotting tools and interfaces to diverse phylogenetic software packages. Retrieved from https://rdrr.io/github/fmichonneau/phyloch/

Hipp, A. L., Manos, P. S., Gonzalez-Rodriguez, A., Hahn, M., Kaproth, M., McVay, J. D., . . Cavender-Bares, J. (2018). Sympatric parallel diversification of major oak clades in the Americas and the origins of Mexican species diversity. New Phytologist, 217(1), 439-452. doi:10.1111/nph.14773

Hoang, D. T., Chernomor, O., von Haeseler, A., Minh, B. Q., \& Le, S. V. (2017). UFBoot2: Improving the ultrafast bootstrap approximation. Molecular Biology and Evolution, msx281. doi:10.1093/molbev/msx281

Hood, G. R., Forbes, A. A., Powell, T. H., Egan, S. P., Hamerlinck, G., Smith, J. J., \& Feder, J. L. (2015). Sequential divergence and the multiplicative origin of community diversity. Proceedings of the National Academy of Sciences of the United States of America, 112(44), E5980-5989. doi:10.1073/pnas.1424717112

Hood, G. R., Zhang, L., Hu, E. G., Ott, J. R., \& Egan, S. P. (2019). Cascading reproductive isolation: Plant phenology drives temporal isolation among populations of a host-specific herbivore. Evolution, 73(3), 554568. doi:10.1111/evo.13683 
Jones, G. (2017). Algorithmic improvements to species delimitation and phylogeny estimation under the multispecies coalescent. Journal of Mathematical Biology, 74(1-2), 447-467. doi:10.1007/s00285-0161034-0

Kaartinen, R., Stone, G. N., Hearn, J., Lohse, K., \& Roslin, T. (2010). Revealing secret liaisons: DNA barcoding changes our understanding of food webs. Ecological Entomology, 35(5), 623-638. doi:10.1111/j.13652311.2010.01224.x

Kalyaanamoorthy, S., Minh, B. Q., Wong, T. K., von Haeseler, A., \& Jermiin, L. S. (2017). ModelFinder: Fast model selection for accurate phylogenetic estimates. Nature Methods, 14(6), 587. doi:10.1038/nmeth.4285

Katoh, K., \& Toh, H. (2008). Recent developments in the MAFFT multiple sequence alignment program. Briefings in Bioinformatics, 9(4), 286-298. doi:10.1093/bib/bbn013

Kimura, M. (1980). A simple method for estimating evolutionary rate of base substitutions through comparative studies of nucleotide sequences. Journal of Molecular Evolution, 16, 111-120. doi:10.1007/BF01731581

Laliberte, E., \& Legendre, P. (2010). A distance-based framework for measuring functional diversity from multiple traits. Ecology, 91, 299-305. doi:10.1890/08-2244.1

Lanfear, R., Calcott, B., Kainer, D., Mayer, C., \& Stamatakis, A. (2014). Selecting optimal partitioning schemes for phylogenomic datasets. BMC Evolutionary Biology, 14(1), 1-14. doi:10.1186/1471-2148-14-82

Lanfear, R., Frandsen, P. B., Wright, A. M., Senfeld, T., \& Calcott, B. (2016). PartitionFinder 2: New methods for selecting partitioned models of evolution for molecular and morphological phylogenetic analyses. Molecular Biology and Evolution, 34(3), 772-773. doi:10.1093/molbev/msw260

Legendre. P., Fortin, M.J., \& Borcard, D. (2015). Should the Mantel test be used in spatial analysis? Methods in Ecology and Evolution, 6, 1239-1247. doi:10.1111/2041-210X.12425

Li, Y., Zhou, X., Feng, G., Hu, H., Niu, L., Hebert, P. D., \& Huang, D. (2010). COI and ITS2 sequences delimit species, reveal cryptic taxa and host specificity of fig-associated Sycophila (Hymenoptera, Eurytomidae). Molecular Ecology Resources, 10(1), 31-40. doi:10.1111/j.1755-0998.2009.02671.x

Longino, J. T., \& Branstetter, M. G. (2021). Integrating UCE phylogenomics with traditional taxonomy reveals a trove of New World Syscia species (Formicidae: Dorylinae). Insect Systematics and Diversity, 5(2). doi:10.1093/isd/ixab001

Lotfalizadeh, H., Delvare, G., \& Rasplus, J. Y. (2008). Sycophila pistacina (Hymenoptera: Eurytomidae): A valid species. European Journal of Entomology, 105(1), 137-147. doi:10.14411/eje.2008.019

Luo, A., Ling, C., Ho, S. Y. W., \& Zhu, C. D. (2018). Comparison of methods for molecular species delimitation across a range of speciation scenarios. Systematic Biology, 67(5), 830-846. doi:10.1093/sysbio/syy011

MacEwen, J., Earley, N., \& Lalonde, R. (2020). How much does the host matter to the parasitoid? Distribution of Eurytoma (Hymenoptera, Chalcidoidea) species amongst two locally co-occurring gall-inducing hosts in the genus Diplolepis (Hymenoptera, Cynipidae). The Canadian Entomologist, 152(6), 815-822. doi: $10.4039 /$ tce. 2020.55

Manos, P.S., \& Hipp, A.L. (2021). An updated infrageneric classification of the North American oaks (Quercus Subgenus Quercus): Review of the contribution of phylogenomic data to biogeography and species diversity. Forests, 12(6), 786. doi:10.3390/f12060786

Martinson, E.O., Werren, J.H., \& Egan, S.P. (2021). Tissue $\square$ specific gene expression shows a cynipid wasp repurposes oak host gene networks to create a complex and novel parasite $\square$ specific organ. Molecular Ecology. doi:10.1111/mec.16159

Melika, G., Pujade-Villar, J., Abe, Y., Tang, C.T., Nicholls, J., Wachi, N., Ide, T., Yang, M.-M., Pénzes, Z., Csóka, G. \& Stone, G.N. (2010). Palaearctic oak gallwasps galling oaks (Quercus) in the section Cerris: reappraisal of generic limits, with descriptions of new genera and species (Hymenoptera: Cynipidae: Cynipini). Zootaxa, 2470, 1-79. doi:10.11646/zootaxa.2470.1.1

Melika, G., Pujade-Villar, J., Nicholls, J.A., Cuesta-Porta, V., Cooke-McEwen, C., \& Stone, G.N. (2021). Three new Nearctic genera of oak cynipid gall wasps (Hymenoptera: Cynipidae: Cynipini): Burnettweldia Pujade-Villar, Melika \& Nicholls, Nichollsiella Melika, Pujade-Villar \& Stone, Disholandricus Melika, Pujade-Villar \& Nicholls; and re-establishment of the genus Paracraspis Weld. Zootaxa, 4993, 1-81. doi:10.11646/ZOOTAXA.4993.1.1

Minh, B. Q., Schmidt, H. A., Chernomor, O., Schrempf, D., Woodhams, M. D., Von Haeseler, A., \& Lanfear, R. (2020). IQ-TREE 2: New models and efficient methods for phylogenetic inference in the genomic era. Molecular Biology and Evolution, 37(5), 1530-1534. doi:10.1093/molbev/msaa015

Nicholls, J. A., Challis, R. J., Mutun, S., \& Stone, G. N. (2012). Mitochondrial barcodes are diagnostic of shared refugia but not species in hybridizing oak gallwasps. Molecular Ecology, 21(16), 4051-4062. doi:10.1111/j.1365-294X.2012.05683.x 
Nicholls, J. A., Melika, G., \& Stone, G. N. (2017). Sweet tetra-trophic interactions: Multiple evolution of nectar secretion, a defensive extended phenotype in cynipid gall wasps. The American Naturalist, 189(1), 67-77. doi:10.1086/689399

Nicholls, J. A., Preuss, S., Hayward, A., Melika, G., Csóka, G., Nieves-Aldrey, J.-L., . . Stone, G. N. (2010). Concordant phylogeography and cryptic speciation in two Western Palaearctic oak gall parasitoid species complexes. Molecular Ecology, 19(3), 592-609. doi:10.1111/j.1365-294X.2009.04499.x

Nicholls, J. A., Schönrogge, K., Preuss, S., \& Stone, G. N. (2018). Partitioning of herbivore hosts across time and food plants promotes diversification in the Megastigmus dorsalis oak gall parasitoid complex. Ecology and Evolution, 8(2), 1300-1315. doi:10.1002/ece3.3712

Noyes, J. S. (2019). Universal Chalcidoidea Database. http://www.nhm.ac.uk/entomology/chalcidoids/index.html (Accessed May 16th, 2021)

Oksanen, J., Guillaume Blanchet, F., Friendly, M., Kindt, R., Legendre, P., McGlinn, D., Minchin, P.R., O’Hara, R.B., Simpson, G.L., Solymos, P., Stevens, M.H.H., Szoecs, \& E., Wagner, H. (2020). Community Ecology Package ('vegan') version 2.5-7. CRAN. https://cran.r-project.org, https://github.com/vegandevs/vegan

Paradis, E., Blomberg, S., Bolker, B., Brown, J., Claramunt, J., Claude, J.,. . . de Vienne, D. (2021). Analysis of Phylogenetics and Evolution ('ape') version 5.5. CRAN. ttp://ape-package.ird.fr/

Page, A.J., Taylor, B., Delaney, A.J., Soares, J., Seemann, T., Keane, J.A., \& Harris, S.R. (2016). SNP-sites: rapid efficient extraction of SNPs from multi-FASTA alignments. Microbial genomics, 2(4). doi:10.1099/mgen.0.000056

Pons, J., Barraclough, T. G., Gomez-Zurita, J., Cardoso, A., Duran, D. P., Hazell, S., . . Vogler, A. P. (2006). Sequence-based species delimitation for the DNA taxonomy of undescribed insects. Systematic Biology, 55(4), 595-609. doi:10.1080/10635150600852011

Prebus, M. M. (2021). Phylogenomic species delimitation in the ants of the Temnothorax salvini group (Hymenoptera: Formicidae): An integrative approach. Systematic Entomology, 46(2), 307-326. doi:10.1111/syen.12463

Price, P. W., Fernandes, G. W., \& Waring, G. L. (1987). Adaptive nature of insect galls. Environmental Entomology, 16(1), 15-24. doi:10.1093/ee/16.1.15

Puillandre, N., Brouillet, S., \& Achaz, G. (2021). ASAP: Assemble species by automatic partitioning. Molecular Ecology Resources, 21(2), 609-620. doi:10.1111/1755-0998.13281

Puillandre, N., Lambert, A., Brouillet, S., \& Achaz, G. (2012). ABGD, Automatic Barcode Gap Discovery for primary species delimitation. Molecular Ecology, 21(8), 1864-1877. doi:10.1111/j.1365294X.2011.05239.x

Rabiee, M., \& Mirarab, S. (2020). SODA: Multi-locus species delimitation using quartet frequencies. Bioinformatics, 36(24), 5623-5631. doi:10.1093/bioinformatics/btaa1010

R Core Team (2021). R: A language and environment for statistical \#\# computing. R Foundation for Statistical Computing, Vienna, Austria. \#\# URL https://www.R-project.org/.

Rambaut, A., Drummond, A. J., Xie, D., Baele, G., \& Suchard, M. A. (2018). Posterior summarization in Bayesian phylogenetics using Tracer 1.7. Systematic Biology, 67(5), 901-904. doi:10.1093/sysbio/syy032

Roberts, D.W. (2019). Ordination and Multivariate Analysis for Ecology ('labdsv') version 2.0-1. CRAN. https://cran.r-project.org/web/packages/labdsv/index.html

Rohfritsch, O., \& Shorthouse, J. D. (1982). Insect galls. In Molecular biology of plant tumors (pp. 131-152): Elsevier.

Rokas, A., Melika, G., Abe, Y., Nieves-Aldrey, J.-L., Cook, J. M., \& Stone, G. N. (2003). Lifecycle closure, lineage sorting, and hybridization revealed in a phylogenetic analysis of European oak gallwasps (Hymenoptera: Cynipidae: Cynipini) using mitochondrial sequence data. Molecular Phylogenetics and Evolution, 26(1), 36-45. doi:10.1016/S1055-7903(02)00329-9

Samacá-Sáenz, E., Egan, S. P., \& Zaldívar-Riverón, A. (2020). Species diversity in the braconid wasp Genus Allorhogas (Doryctinae) associated with cynipid galls on Live Oaks (Quercus: Fagaceae) using natural history, phylogenetics, and morphology. Insect Systematics and Diversity, 4(5). doi:10.1093/isd/ixaa011

Sinclair, F.H., Stone, G.N., Nicholls, J.A., Cavers, S., Gibbs, M., Butterill, P., Wagner, S., Ducousso, A., Gerber, S., Petit, R.J., \& Kremer, A. (2015). Impacts of local adaptation of forest trees on associations with herbivorous insects: implications for adaptive forest management. Evolutionary Applications, 8(10), 972987. doi:10.1111/eva.12329 
Schönrogge, K., Stone, G., \& Crawley, M. (1996). Alien herbivores and native parasitoids: rapid developments and structure of the parasitoid and inquiline complex in an invading gall wasp Andricus quercuscalicis (Hymenoptera: Cynipidae). Ecological Entomology, 21(1), 71-80.

Schwallier, R., Raes, N., de Boer, H.J., Vos, R.A., van Vugt, R.R., \& Gravendeel, B. (2016). Phylogenetic analysis of niche divergence reveals distinct evolutionary histories and climate change implications for tropical carnivorous pitcher plants. Diversity and Distributions, 22(1), 97-110. doi:10.1111/ddi.12382

Sheikh, S. I., Ward, A. K. G., Zhang, Y. M., Davis, C. K., Zhang, L., Egan, S. P., \& Forbes, A. A. (2021). Ormyrus labotus Walker (Hymenoptera: Ormyridae): another generalist that should not be a generalist is not a generalist. bioRxiv, 10.26.465982. doi:10.1101/2021.10.26.465982

Smith-Freedman, C. J., Andersen, J. C., Griffin, B. P., Schick, K., \& Elkinton, J. S. (2019). Rise and fall of an oak gall wasp (Hymenoptera: Cynipidae) outbreak in Massachusetts. Environmental Entomology, 48(6), 1277 1285. doi:10.1093/ee/nvz115

Stamatakis, A. (2006). RAxML-VI-HPC: maximum likelihood-based phylogenetic analyses with thousands of taxa and mixed models. Bioinformatics, 22(21), 2688-2690. doi:10.1093/bioinformatics/btl446

Stone, G. N., \& Cook, J. M. (1998). The structure of cynipid oak galls patterns in the evolution of an extended phenotype. Proceedings of the Royal Society of London B: Biological Sciences, 265(1400), 979-988. doi:10.1098/rspb.1998.0387

Stone, G. N., Lohse, K., Nicholls, J. A., Fuentes-Utrilla, P., Sinclair, F., Schönrogge, K., . . Pujade-Villar, J. (2012). Reconstructing community assembly in time and space reveals enemy escape in a Western Palearctic insect community. Current Biology, 22(6), 532-537. doi:10.1016/j.cub.2012.01.059

Stone, G. N., \& Schönrogge, K. (2003). The adaptive significance of insect gall morphology. Trends in Ecology \& Evolution, 18(10), 512-522. doi:10.1016/s0169-5347(03)00247-7

Stone, G. N., Schönrogge, K., Atkinson, R. J., Bellido, D., \& Pujade-Villar, J. (2002). The population biology of oak gall wasps (Hymenoptera Cynipidae). Annual Review of Entomology, 47(1), 633-668. doi:10.1146/annurev.ento.47.091201.145247

Sukumaran, J., \& Knowles, L. L. (2017). Multispecies coalescent delimits structure, not species. Proceedings of the National Academy of Sciences, 114(7), 1607-1612. doi:10.1073/pnas.1607921114

Tagliacollo, V. A., \& Lanfear, R. (2018). Estimating improved partitioning schemes for ultraconserved elements. Molecular Biology and Evolution, 35(7), 1798-1811. doi:10.1093/molbev/msy069

Tamura, K., Stecher, G., \& Kumar, S. (2021). MEGA11: molecular evolutionary genetics analysis version 11. Molecular Biology and Evolution, 38(7), 3022-3027. doi:10.1093/molbev/msab120

Tang, C-T, Melika G, Yang M-M, Nicholls J, \& Stone GN (2011). A new genus of oak gallwasps, Cycloneuroterus Melika \& Tang, with the description of five new species from Taiwan (Hymenoptera: Cynipidae: Cynipini). Zootaxa, 3008, 33-62. doi:10.11646/zootaxa.3008.1.2

Walton, W., Stone, G. N., \& Lohse, K. (2021). Discordant Pleistocene population size histories in a guild of hymenopteran parasitoids. Molecular Ecology, 30, 4538- 4550. doi:10.1111/mec.16074

Ward, A. K. G., Khodor, O. S., Egan, S. P., Weinersmith, K. L., \& Forbes, A. A. (2019). A keeper of many crypts: A behaviour-manipulating parasite attacks a taxonomically diverse array of oak gall wasp species. Biology Letters, 15(9), 20190428. doi:10.1098/rsbl.2019.0428

Ward, A. K. G., Sheikh, S. I., \& Forbes, A. A. (2020). Diversity, host ranges, and potential drivers of speciation among the inquiline enemies of oak gall wasps (Hymenoptera: Cynipidae). Insect Systematics and Diversity, 4(6), 1-13. doi:10.1093/isd/ixaa017

Weinersmith, K. L., Forbes, A. A., Ward, A. K. G., Brandão-Dias, P. F. P., Zhang, Y. M., Egan, S. P., \& Shi, P. (2020). Arthropod community associated with the asexual generation of Bassettia pallida (Hymenoptera: Cynipidae). Annals of the Entomological Society of America, 113(5), 373-388. doi:10.1093/aesa/saaa009

Weinersmith, K. L., Liu, S. M., Forbes, A. A., \& Egan, S. P. (2017). Tales from the crypt: a parasitoid manipulates the behaviour of its parasite host. Proceedings of the Royal Society B: Biological Sciences, 284(1847). doi:10.1098/rspb.2016.2365

Weld, L. H. (1957). Cynipid galls of the Pacific Slope. Ann Arbor, Michigan, USA: Privately Printed.

Weld, L. H. (1959). Cynipid galls of Eastern United States. Ann Arbor, Michigan, USA: Privately Printed.

Weld, L. H. (1960). Cynipid galls of the Southwest. Ann Arbor, Michigan, USA: Privately Printed.

Yang, Z. (2015). The BPP program for species tree estimation and species delimitation. Current Zoology, 61(5), 854-865. doi:10.1093/czoolo/61.5.854

Zhang, J., Kapli, P., Pavlidis, P., \& Stamatakis, A. (2013). A general species delimitation method with applications to phylogenetic placements. Bioinformatics, 29(22), 2869-2876. doi:10.1093/bioinformatics/btt499 
Zhang, L., Hood, G. R., Ott, J. R., \& Egan, S. P. (2019). Temporal isolation between sympatric host plants cascades across multiple trophic levels of host-associated insects. Biology Letters, 15(12), 20190572. doi:10.1098/rsbl.2019.0572

Zhang, Y. M., Buffington, M. L., Looney, C., Laszlo, Z., Shorthouse, J. D., Ide, T., \& Lucky, A. (2020). UCE data reveal multiple origins of rose gallers in North America: global phylogeny of Diplolepis Geoffroy (Hymenoptera: Cynipidae). Molecular Phylogenetics and Evolution, 153, 106949. doi:10.1016/j.ympev.2020.106949

Zhang, Y. M., Egan, S. P., Driscoe, A. L., \& Ott, J. R. (2021). One hundred and sixty years of taxonomic confusion resolved: Belonocnema (Hymenoptera: Cynipidae: Cynipini) gall wasps associated with live oaks in the USA. Zoological Journal of the Linnean Society, 193(4), 1234-1255. doi:10.1093/zoolinnean/zlab001

Zhang, Y. M., Gates, M. W., \& Shorthouse, J. D. (2014). Testing species limits of Eurytomidae (Hymenoptera) associated with galls induced by Diplolepis (Hymenoptera: Cynipidae) in Canada using an integrative approach. The Canadian Entomologist, 146(3), 321-334. doi:10.4039/tce.2013.70

Zhang, Y. M., László, Z., Looney, C., Dénes, A.-L., Hanner, R. H., \& Shorthouse, J. D. (2019a). DNA barcodes reveal inconsistent species boundaries in Diplolepis rose gall wasps and their Periclistus inquilines (Hymenoptera: Cynipidae). The Canadian Entomologist, 151(6), 717-727. doi:10.4039/tce.2019.59

Zhang, Y. M., Williams, J. L., \& Lucky, A. (2019b). Understanding UCEs: A comprehensive primer on using ultraconserved elements for arthropod phylogenomics. Insect Systematics and Diversity, 3(5), 3. doi:10.1093/isd/ixz016

Table 1. Summary of Sycophila COI morphospecies and their host range, bold indicates clades with COI and UCE data. Symbols $\left(\$ \#^{\wedge}\right)$ indicates the clades are grouped together in UCE data. Tree Sections $Q=$ Quercus s.s., $\mathrm{P}=$ Protobalanus, $\mathrm{L}=$ Lobatae, $\mathrm{V}=$ Virentes; Regions $\mathrm{E}=$ Eastern US; $\mathrm{S}=$ Southwestern US, $\mathrm{P}$ = Pacific Slopes.

\begin{tabular}{|c|c|c|c|c|}
\hline Morphospecies & \# of host galls & \# of host trees & Tree sections & Regions \\
\hline quercilanae & 12 & 7 & $\mathrm{Q} / \mathrm{L}$ & $\mathrm{E}$ \\
\hline pezomachiodes $^{\wedge}$ & 1 & 1 & Q & S \\
\hline lobatae $^{\wedge}$ & 1 & 1 & $\mathrm{P}$ & $\mathrm{P}$ \\
\hline foliatae $^{\#}$ & 8 & 4 & $\mathrm{Q} / \mathrm{V}$ & $\mathrm{E}$ \\
\hline nr.lanae & 1 & 1 & $\mathrm{~L}$ & $\mathrm{E}$ \\
\hline $\mathrm{nr}$.foliatae $-\mathbf{1}^{\#}$ & 1 & 2 & Q & $\mathrm{E}$ \\
\hline $\mathrm{nr}$.foliatae-2 & 1 & 1 & $\mathrm{~L}$ & $\mathrm{E}$ \\
\hline sp1 & 1 & 2 & V & $\mathrm{E}$ \\
\hline $\mathrm{sp} 2$ & 1 & 2 & V & $\mathrm{E}$ \\
\hline $\mathrm{sp} 3$ & 2 & 2 & $\mathrm{~L}$ & $\mathrm{E}$ \\
\hline sp4 & 2 & 2 & $\mathrm{Q} / \mathrm{L}$ & $\mathrm{E} / \mathrm{S}$ \\
\hline marylandica & 5 & 4 & $\mathrm{Q} / \mathrm{L}$ & $\mathrm{E}$ \\
\hline wiltzae & 1 & 1 & Q & $\mathrm{P}$ \\
\hline varians & 1 & 1 & $\mathrm{~L}$ & $\mathrm{E}$ \\
\hline
\end{tabular}




\begin{tabular}{|c|c|c|c|c|}
\hline sp5-1 & 1 & 1 & $\mathrm{~L}$ & $\mathrm{E}$ \\
\hline sp5-2 & 1 & 1 & $\mathrm{~L}$ & $\mathrm{E}$ \\
\hline $\mathrm{nr}$.flava & 1 & 1 & $\mathrm{~L}$ & $\mathrm{E}$ \\
\hline flavaltexana & 4 & 3 & Q & $\mathrm{E} / \mathrm{S}$ \\
\hline flava & 1 & 1 & Q & $\mathrm{E}$ \\
\hline texana & 4 & 3 & Q & $\mathrm{E} / \mathrm{S}$ \\
\hline sp6 & 1 & 1 & $\mathrm{~L}$ & $\mathrm{E}$ \\
\hline nr.nubilistigma & 3 & 3 & $\mathrm{~L}$ & $\mathrm{E}$ \\
\hline nr.globuli & 1 & 1 & $\mathrm{~L}$ & $\mathrm{E}$ \\
\hline nr.dubia/globuli & 3 & 3 & $\mathrm{Q} / \mathrm{L}$ & $\mathrm{E} / \mathrm{P}$ \\
\hline sp7 & 1 & 1 & V & $\mathrm{S}$ \\
\hline nr.lobatae & 1 & 1 & $\mathrm{~L}$ & $\mathrm{P}$ \\
\hline dubia-1 & 1 & 1 & $\mathrm{~L}$ & $\mathrm{E}$ \\
\hline dubia-2 & 1 & 1 & $\mathrm{~L}$ & $\mathrm{E}$ \\
\hline nr.nigriceps-1 & 1 & 1 & $\mathrm{~L}$ & $\mathrm{E}$ \\
\hline nr.nigriceps-2 $\mathbf{2}^{\$}$ & 1 & 1 & Q & $\mathrm{E}$ \\
\hline nr.occidentalis ${ }^{\$}$ & 2 & 1 & Q & $\mathrm{P}$ \\
\hline sp8 & 1 & 1 & Q & $\mathrm{S}$ \\
\hline globuli & 2 & 3 & Q & $\mathrm{E} / \mathrm{S}$ \\
\hline nr.wiltzae & 1 & 1 & Q & $\mathrm{P}$ \\
\hline sp9 & 1 & 1 & Q & $\mathrm{E}$ \\
\hline
\end{tabular}

942 Table S1. Collection information for Sycophila samples, including GenBank/SRA accession numbers.

943 Table S2. A table of the gall morphological traits.

944 Table S3. Intraspecific divergence of Sycophila COI species, calculated using Kimura-2-parameter.

945 Table S4. Interspecific divergence of Sycophila COI species, calculated using Kimura-2-parameter.

946 Table S5. Gall wasp and Sycophila interaction matrix. 
Figure 1. A. Sycophila sp. ovipositing into a detachable leaf gall of Acraspis pezomachioides. B. Wooly bud gall of Callirhytis seminator with larval chambers. C. Integral stem gall of Callirhytis quercuspuncatata with exit holes. D. Cross-section of woody stem gall of Disholcaspis quercusglobulus. E. Free-rolling larval chamber of integral leaf gall of Dryocosmus quercuspalustris. F. Camponotus ants feeding on nectars secreted by the gall of Disholcaspis quercusmamma. Photo A by Carroll Perkins, B/D by Anna Ward, C/F by Jeff Clark, D by Charley Eiseman.

Figure 2. Overview of all COI data used in inferring Sycophila diversity associated with North American oak galls. Left: simplified COI phylogeny of Sycophila included in this study (see Supp Fig. $X$ for full tree). Bootstrap support indicated on nodes. 'Identification' describes putative species assignments based on the sum of information to the right of this column. ASAP, bPTP, and GYMC columns indicate assignments of individuals into groups by these respective algorithms. 'Oak Section', 'Plant Tissue', 'External Gall Morphology', 'Internal Gall Morphology' and 'Gall Generation Attacked' refer to ecological characters for Sycophila in each clade, and example photos of galls are shown in Fig. SX. Abbreviations as follows: External Gall Morphology: $\mathrm{Br}=$ Leaf Bract, $\mathrm{S}=$ Smooth, $\mathrm{N}=$ Nectar, $\mathrm{T}=$ Textured, $\mathrm{Sp}=$ Spines, $\mathrm{Wl}=$ Wool, Int $=$ Integral, Det $=$ Detachable; Internal Gall Morphology: $W=$ Woody, $\mathrm{H}=$ Hollow, $F=$ Fleshy, FR $=$ FreeRolling, RF = Radiating Fiber.

Figure 3. Overview of all UCE data used in inferring Sycophila diversity associated with North American oak galls. Left: Allelic phased UCE phylogeny of Sycophila using STACEY. SODA and BPP columns indicate assignments of individuals into groups by these respective algorithms. 'Identification' describes putative species assignments based on the sum of information to the left of this column.

Figure 4. Biplots of PCoA1 and PCoA2 of A) gall wasps species plotted in gall wasp trait space, and B) centroids of Sycophila species of gall wasp species they interact with, representing "interaction" trait space. Dark symbols represent gall wasp species (diamonds) and Sycophila species (triangles). Red arrows represent trait loadings. Species acronyms found in Table S2. The loadings for the following traits, spines, nectar, fiber, and rolling are not plotted, occurring near the center $(*)$.

Figure S1. Summary and identification of Sycophila included in this study.

Figure S2. Photo of galls included in this study, all photos by authors except for Callirhytis perdens by Leslie Flint, Disholcaspis edura by Mike Plagens, and Zapatella davisae by Kelly Omand.

Figure S3. Full COI phylogeny of Sycophila associated with oak galls. Nodal support represents bootstrap pseudoreplicates.

Figure S4. Full UCE phylogeny of Sycophila associated with oak galls. Dots at the nodes represent strong support for Ultrafast Bootstrap ( $\geq 95)$ and SH-aLRT $(\geq 80)$.

Figure S5. Scatter plot of net evolutionary divergence and distance in interaction trait space between each pairwise combination of Sycophila species. 
bioRxiv preprint doi: https://doi.org/10.1101/2022.01.21.477213; this version posted January 23, 2022. The copyright holder for this preprint (which was not certified by peer review) is the author/funder. All rights reserved. No reuse allowed without permission.
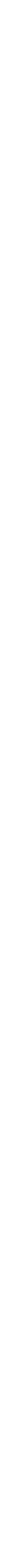
STACEY

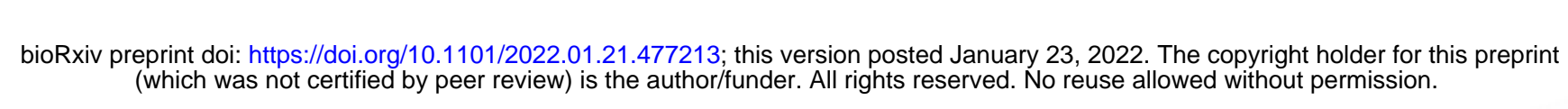




\section{3}

A

bioRxiv preprint doi: https://doi.org/10.1101/2022.01.21.477213; this version posted January 23, 2022. The copyright holder for this preprint (which was not certified by peer review) is the author/funder. All rights reserved. No reuse allowed without permission.
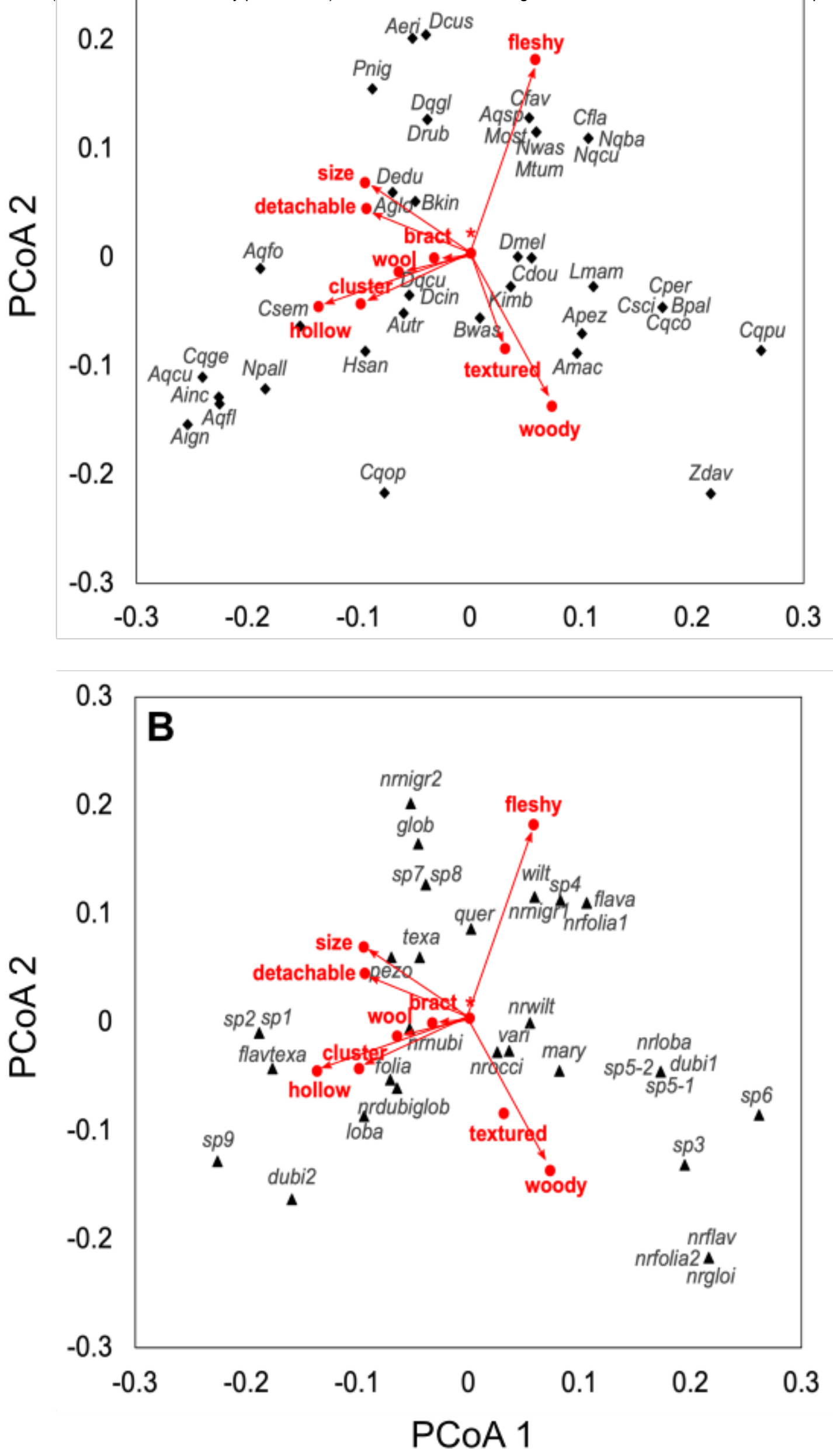